\title{
Family Roles in Developing Resilience Skills in School Children with Autism Spectrum Disorders
}

\author{
Charity N. Onyishi ${ }^{1,2} \&$ Maximus M. Sefotho ${ }^{1}$ \\ ${ }^{1}$ Department of Educational Psychology, University of Johannesburg, South Africa \\ ${ }^{2}$ University of Nigeria, Nsukka, Nigeria \\ Correspondence: Charity N Onyishi, Department of Educational Psychology, University of Johannesburg, \\ South-Africa. ORCID: 0000-0003-4047-7850. E-mail: cnonyishi@uj.ac.za
}

Received: September 18, 2019 Accepted: November 5, 2019 Online Published: December 12, 2019

doi:10.5539/gjhs.v11n14p81

URL: https://doi.org/10.5539/gjhs.v11n14p81

\begin{abstract}
Children with Autism Spectrum (ASD) Disorders are highly vulnerable and constitute significant burdens on the families, schools and the global economy. Developing resilience in children with autism spectrum disorders is a major challenge to both teachers and parents. This article discusses the roles of the family in building resilience among children with ASD. Firstly, the article explored the roles of parents in developing resilience in children with ASD. Secondly, the roles of siblings in developing resilience in children with ASD were examined. Thirdly, the roles of family socio-economic/cultural contexts in developing resilience in children with ASD were investigated. Finally, we discussed researches on best practices for resilience in children with ASD and directions for educational practices and future research.
\end{abstract}

Keywords: resilience skills, families, children with ASD

\section{Introduction}

The increasing prevalence of autism spectrum disorder worldwide in recent times is a global challenge and has been of considerable research interest. 1 in 59 children worldwide is living with autism (Centre for Disease Control, 2018). In Africa, around 1.5-3\% of children are living with ASD (Abubakar, Ssewanyana, \& Newton, 2016; Bakare\&Munir, 2011). Prevalence ranges from 2.3\% to $2.9 \%$ among children with other disabilities (Franz, Chambers, von Isenburg, \& de Vries, 2017; Lagunju, Bella-Awusah, \& Omigbodun, 2014), and about $1.1 \%$ in general Education settings (Essien, Akpan, \& Ekanem, 2017) in Nigeria. For instance, in Nigeria, Eseigbe, Nuhu, Sheikh, Eseigbe, Sanni and Olisa (2014) predicted that about 600,000 Nigerian children are living with ASD, and such individuals qualify for special education and remedial interventions both in the schools and families (Individuals with Disabilities Education Act (IDEA), 2004; Smith et al., 2014). It is also estimated that about 270 000 south-Africans are living with ASD (Van Biljon, Kritzinger, \& Geertsema, 2015). Just as across the world, autism prevalence has experienced unprecedented increase in sub-saharan Africa within the last decade (Franz, et al., 2017).

The defining contexts of Africa around ASD is characterized by poor knowledge among health professional (Eseigbe et al., 2014), Educational professionals (Odunsi, Garner, \& Preece, 2017) and the families (Chukwueloka, 2016), together with high neurological comorbidities (Bakare \& Munir, 2011b; Lagunju et al., 2014). Poor knowledge of the disorder about the prognosis and nature of ASD suggests that both special Educators and affected families may still be uncertain about their roles in improving the conditions of children with ASD in the school and at home.

Developing resilience skills is necessary for positive adaptation and functioning in different areas of life, in both autistic and bio-typical populations (Smith \& Anderson, 2014; Wright, Masten, \& Narayan, 2013).

Resilience is a dynamic process that enables an individual to adapt functionally and/or withstand significant risks and threatening circumstances to stability, viability, or development (Masten \& Tellegen, 2012). Resilience in children with ASD reduces physical, economic and psychological burdens on the ASD families (Picardiet al., 2018), and provides the children with ASD with the impetus to demonstrate positive outcomes in independency, transitions, occupational growth and eventual career success during adulthood in spite of threats (Lai \& Szatmari, 2019). ASDs are typified in poor social and communicative interactions, as well as repetitive stereotyped 
behaviours (American Psychiatric Association, 2013). These characteristic deficits collectively impede the individuals' abilities to adapt to new routines or function adaptively in and outside the families, compared to their typically developing peers (Martínez-Pedraza \& Carter, 2009). Children in this spectrum tend to find most normal changes in life very threatening and awful (Smith, \& Anderson, 2014), especially when they are not resilient. These tend to worsen as the child goes through the trajectory of development and life experiences. For instance, when enrolled in school environments, children with ASD encounters an array of social, academic and psycho-personal challenges that constitute a threat to the children.

Additionally, in most African countries, the socio-economic and cultural threats, as well as lack of awareness of ASD and the cultural stigma associated with ASD condition jointly increase the vulnerability of children with ASD (Bakare \& Munir, 2011). Moreover, the majority of autistic school children in the area demonstrate poor functionality and dependence in almost all domains of life (Bakare \& Munir, 2011), evincing poor resilience. These stereotyped challenges among the children with ASD in Africa equally make their development of resilience imperative and at the same time highlight the need for both school and family's commitments in developing resilience in children with ASD. On the other hand, the proliferating prevalence of ASD across the world (APA, 2013), and in Africa in particular (Bakare \& Munir, 2011; Essien, Akpan, \& Ekanem, 2017; Lagunju, Bella-Awusah \& Omigbodun, 2014) brings to bear, the need to intensify research on how to improve productivity among individuals in the spectrum. However, less research attention has been given to building resilience in children with ASD (Szatmari, 2018)

This article discusses the roles of the family in developing resilience among children with ASD. Firstly, the roles of parents in developing resilience in their children with ASD were discussed. Secondly, we explored the roles of siblings in developing resilience in autistic children. Further, the roles of family systems were highlighted and discussed. Finally, researches on best practices for developing resilience in ASD children; and directions for future research and Educational practices were discussed.

\section{Family System and Resilience in Their Children with ASDs}

\subsection{The Role of the Parents in Building Resilience in children with ASD}

Research shows a link between parenting behaviours and the development of children with ASD in different domains (Crowell, Keluskar, \& Gorecki, 2019). Positive parenting has been linked with enhanced language trajectories in ASD children (Siller \& Sigman, 2002, 2008), and the ability to live independent functional life (Crowell, Keluskar, \&Gorecki, 2019). For instance,Harker, Ibanez, Nguyen, Messinger, and Stone (2016) showed the family's critical role in healthily managing feelings and emotions among children with ASD in their study on the effect of parenting style on social smiling in infants at high and low risk for ASD. The study showed that maternal directiveness led to high social smiling infants with a high risk of ASDs. The result further indicated that each parenting style made a unique impact on social engagement in infants at high- and low-risk for ASDs. Ostfeld-Etzion, Golan, Hirschler-Guttenberg, Zagoory-Sharon, and Feldman, (2015) found that maternal presence and regulation facilitation provided social buffering for the children with ASDs' hypothalamic-pituitary-adrenal (HPA) stress response like mammalian neonates. This implied that poor social behaviour in high-risk infants as opposed to complex social behaviours of gestures and language may be masked through maternal behaviour. In a similar study, Ostfeld-Etzion, Golan, Hirschler-Guttenberg, Zagoory-Sharon, and Feldman, (2015) found that parents' emotional support and cohesive structuring were linked with social skills of both typically developing (TD) and children with ASD at pre-school.

Study shows that when controlling for child's age and intelligent quotient, parents' emotional scaffolding predicted externalizing problem behaviours (Ting \& Weiss, 2017). The authors explained that through emotionalscaffolding, parents help their child's emotional development by being responsive to their child and helping their child to sustain persistence in a task. Parents, through scaffolded prompting, can initiate child-led experiences that could bring about a person-environment fit in school-age children with ASD. Patterson, Elder, Gulsrud, and Kasari (2014) investigated the association between parental interaction style and children's joint engagement in families with toddlers with autism. Findings showed that maternal responsiveness predicted child-initiated joint attention in 2-3-year-olds with ASD, whereas mother-initiated joint attention was predicted by maternal directiveness.

As in typically developing population, parents' criticism and negative emotion have been found to predict behavioural problems in autistic children, adolescents and adults (Boonen, Maljaars, Lambrechts, Zink, Van Leeuwen, \& Noens, 2014). On the other hand, the ability and disposition of the parents to help their child to initiate enthusiasm and persistence toward an activity (emotional scaffolding) through reinforcement and support can help redirect attention back to a given task and increase problem-solving skills (Gulsrud, Jahromi, \& Kasari, 2010). 
In a study to explore attachment security in children with autism, Capps, Sigman, and Mundy (1994) found that children with ASD, independent of developmental quotient develop a secure attachment with the mother which can be extended to others in keeping joint attention. Secure attachments with children with ASD have been found to predict their play behaviour with peers and adults. Research has further shown that when the father is positively sensitive and verbally responsive, to his ASD child, the child develops higher language necessary for initiating and sustaining positive relationships (Flippin \& Watson, 2015).

The role of the family in the educational outcomes of students with autism is also critical. A key resilience skill children with ASD can acquire is the ability to benefit from educational experiences (Roux, Shattuck, Rast, Rava, \& Anderson, 2015). To benefit from educational experience and develop resilience in education and learning, children with autism conditions qualify for special education and individualized instructions (Barnhill, Polloway, \& Sumutka, 2011), as well as additional family, supports at all developmental levels (Carbone, Behl, Azor, \& Murphy, 2010). Parents have consistently been found to be of significant impact on the educational success of their children with ASD (Carbone, Behl, Azor, \& Murphy, 2010; Garbacz, McIntyre, \& Santiago, 2016).

Researches tend to suggest that both academic and behavioural outcomes of students with ASD are improved through family-school collaboration in the child's learning and remedial efforts (Garbacz, McIntosh, Eagle, Dowd-Eagle, Ruppert, Hirano, 2015; Garbacz, Sheridan, Koziol, Kwon, \& Holmes, 2015). Family involvement parenting behaviours that support children's learning (Minke, Sheridan, Kim, Ryoo, \&Koziol, 2014) has further been linked with acquisition of social-emotional skills, indexing resilience in children with autism (Sheridan, Ryoo, Garbacz, Kunz, \& Chumney, 2013; Zablotsky, Boswell, \& Smith, 2012).

\subsection{The Role of Typically Developing Siblings in Resilience of children with ASD}

Siblings constitute a significant part of the familial social circle that can play an influential role in building resilience in children with ASD. This area has been neglected in research possibly due to the putative assumption of the negative impact of an autistic condition could have on members of the family (Helps, 2016; Woo, 2009). The children spend most of their time with their siblings in social reciprocity and transactional engagements.

Literature has documented both positive and negative influences of siblings' relationships in children and adolescents (McHale, Updegraff, \& Feinberg, 2016). Sibling tends to expose children with ASD to early socialization that forms the basis for more successful peer interactions during school age and adolescents (Feinberg, Sakuma, Hostetler, \& McHale, 2013; Lindsay, 2009). From childhood through adolescence, and even into adulthood, sibling relationships are influential children's development (McHale, Updegraff, \& Feinberg, 2016; McHale, Updegraff, \& Whiteman, 2012). Positive sibling relationships enhance psychological health, social competence, school adjustment, peer and romantic relationships and reduce risk behaviours (McHale, Updegraff, \& Feinberg, 2016). Typically developing siblings can have a transactional relationship with the autistic ones in the family, which if well managed could build resilience in both (O'Brien, Slaughter, \& Peterson 2011). When siblings of ASD children possess skills for social problem solving and reinforce positive behaviours with compliments and praise, resilience is improved in their ASD brother or sister (Feinberg, Sakuma, Hostetler, \& McHale, 2013).

Relationships with the siblings can serve as a training ground for problem behaviours or development of resilience skills depending on the direction of the transactional relativity (Feinberg, Sakuma, Hostetler, \& McHale, 2013; Wright, \& Benigno, 2019). children with ASD who learn behaviours from their relationships with their TD siblings can generalize the learned behaviour/skills to other settings (DeCaroli \& Sagone, 2013; Wright \& Benigno, 2019). Research shows that TD siblings of ASD children are always concerned about their brothers' or sisters'behaviours which they find to be incomprehensible (De Caroli \& Sagone, 2013).

Given these relational perspectives, siblings can partake in training and coaching their ASD brother or sister. For instance, a sibling at a childhood stage could support his/her ASD sibling in developing social relationships through play. During school age, they tend to be protective in school, offering social advocacy (Bekhet, Johnson, \& Zauszniewski, 2012). They can offer supports in helping in self-care processes through guidance; and can strengthen the social and communication skills of ASD ones through rich social interaction (Walsh, 2016). They can model expected behaviours if they realize the concept of ASD and the plight of their sibling victims.

Siblings if trained on daily problem-solving skills relating to ASD can capitalize on informal family-based experiences and interactions to bring about positive outcomes and resilience in their ASD sibling (Cridland, Jones, Magee, \& Caputi, 2014; McHale, Updegraff, \& Whiteman, 2012; Woo, 2009). Evidence shows that typical peers, including siblings, can interact more frequently and effectively with children with ASD when they are given the right information about strategies they can use (Kamps, Thiemann-Borque, Heitzman-Powell, et al., 2015). 


\subsection{The Role of Family Socio-Cultural Contexts in Developing Resilience in children with ASD}

From a Family system (FS) perspective, families are distinct, interactive and social systems within which the roles and responsibilities of each member are meant to guide behaviours for the collective functioning of the system (Cridland, Jones, Magee, \& Caputi, 2014; Edwards, 2011). A study has outlined the importance of family context in intervention and support of children with ASD (Cridland, Jones, Magee, \& Caputi, 2014; Walsh, 2016). Bringing up children with ASD to be resilient requires large human commitments and family environments/contexts that cater to their complex needs (McHale, Updegraff, \& Feinberg, 2016).

Family dynamics work together to create a unit of the social-emotional and educational environment for transactional relationships between the children with ASD and their typically developing siblings, as well as their parents. Such family dynamics include family organizational patterns, family problem-solving and family belief systems (Lai \& Szatmari, 2019; Walsh, 2016). Resilience factors in children with ASD are built within the family system through the interactive dictates of the family dynamics (Carrillo, 2012; Walsh, 2016), and strengthened in the school. Organizational patterns of the family include family flexibility, connectedness, and socioeconomic status (Simelane, 2015). Evidence shows that flexible families tend to adopt family roles faster to suit children with ASD after diagnosis and consequently record the better outcome in their child's development (Seligman \& Darling, 2007). Flexible families utilize support services, therapies and are malleable to changing circumstances that could result in developing resilience in children with ASD and all family members (Seligman \& Darling, 2007).

Family connectedness entails the family's ability to develop and maintain internal and external social networks. Social bonds evinced in family cohesion (intra-family connectedness) and links with extended families, teachers, health professionals and therapists, not only help the family to be resilient but also brings insights into supports and interventions needed for building resilience in children with ASD (Bush, Cohen, Eisenhower, \& Blacher, 2017). The socio-economic status of the family tends to predict the quality and quantity of intervention given to children with ASD. ASD is financially demanding in areas of care and interventions to bring about resilience outcomes (Lesi et al., 2014; Lord \& Bishop, 2010).

Evidence indicates that lower familial socio-economic status is linked with greater depression, stress, and anxiety among fathers, and their child's ASD symptom severity or functioning (Mathew, Burton, Schierbeek, Črnčec, Walter, \& Eapen, 2019). Higher familial socio-economic status and greater neighbourhood advantage predict increased adaptive functioning and reduced symptoms in ASD children (Mathew et al., 2019). Conversely, families with low socioeconomic status may lack the finances and necessary information for family-based interventions that could improve resilience (Dawson, 2011). Social support given to ASD children is also linked to the educational level of the parents. Well-educated parent are more responsive to, and have higher expectations for their children with ASD (Bush et al., 2017), compared to low level or uneducated parents who are characterized by, parental distress, parent-child dysfunctional interaction, difficulties understanding why the child is the way he/she is (Bekhet, Johnson, \& Zauszniewski, 2012).

Family problem solving (FPS) and resilience is another dynamic family feature that could come to play in the development of resilience in students children with ASD (Lai \& Szatmari, 2019; Walsh, 2016). It explains the strengths expressed by families in response to a crisis or chronic adversities (Walsh, 2016). FPS is embedded in such attributes as collaborative problem solving/ proactive disposition, clear routines, emotional sharing and acceptance and care (Walsh, 2010; 2016). FPS is the foundation upon which the resilience of children with ASD is built. Yorke, White, Weston, Rafia, Charman, and Simonoff, (2018) showed that resilient families are more likely to cope psychologically with the ASD condition of their children and are less likely to adopt negative behaviours towards children with ASD. Other researches affirm the strong relationship between dimensions of FPS such as clear routines, emotional sharing, and acceptance with children with ASD's adaptation (Schaaf et al., 2011; Ting \& Weiss, 2017).

Family belief systems (FBS) are family outlooks about their circumstances that form the basis upon which families are organized. Belief systems include but not limited to family culture, positivism, hope, spirituality, and faith, as well as attribution and expectations (Glantz \& Johnson, 1999; Walsh, 2016). These FBS also play significant roles in building resilience in children with ASD (Bankole, 2016; Walsh, 2016). The family perception about the causes and prognosis of ASD has also been found to determine their openness to intervention and treatment efforts to improve on their children's care (Ennis-Cole, Durodoye, \& Harris, 2013). 


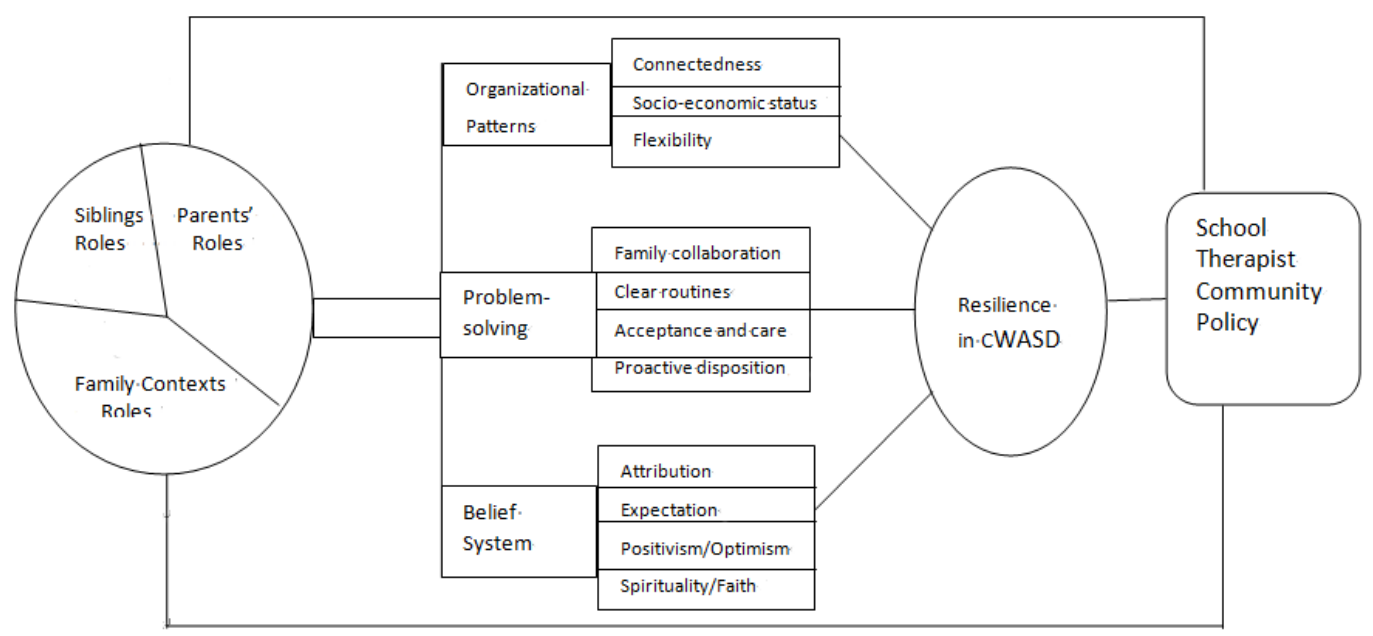

Figure 1. Summary of transactional roles of family systems in developing resilience in children with ASD

The interactive roles of family variables and how they can work with external factors in building resilience in children with ASD are shown above (Figure 1). The family system includes ecological relationships, where parents, siblings and the family socio-cultural contexts work together to bring about resilience in children with ASD. The figure also highlights the place of collaboration with educators, therapists, community and the policy-makers.

\section{Best Practices for Developing Resilience in Children with ASD}

Family involvement is pivotal when considering the best practices in building resilience in children with ASD. The child with ASD spends all their time either in the school, with the teachers or in the family, with the parents/caregivers and the siblings, in the family social-economic and emotional context (Wright \& Benigno, 2019). Connecting the family in this respect could involve empowering the family economically, training both the parents and the siblings on behavioural supports and intervention for improving resilience in children with autism researchers on resilience and ASD have always sought to find out and/or build resilience in other family members of children with ASD (Gardiner, Mâsse, \& Iarocci, 2019; Helps, 2016; Woo, 2009), ignoring the affected children who need resilience skills the most (Lai \& Szatmari, 2019). Future research should seek to fill this gap.

Extant studies show that resilience in children with ASD can mask the major phenotypicalbehavioural symptoms of ASD (Kaboski, Mc Donnell, \& Velentino, 2017; Rodgers, Ozonoff \& Hansen, 3013), thus improving their functionality and participation. With effective collaboration with families of children with ASD, the exchange of ideas of peculiarity about how best to bring about positive educational, behavioural and social outcomes in the child could be shared. This is more crucial given the heterogeneity of children in the spectrum (Kaboski et al., 2017). Information is needed from the family on the details of the child's condition for remedial intervention in the school and even at adulthood (Rowbothan, Carroll, \& Cuskelly, 2011).

Furthermore, engaging in training parents and siblings of children with ASD may be a cost-effective way of bringing about resilience in children with ASD. El Nokali, Bachman, and Votruba-Drzal (2010) found that involving parents in elementary school years accounted for improved social skills and reduced behaviour problems in children with ASD. Educators and interventionists will achieve more positive outcomes when they partner with parents in assessment, evaluation, identifying goals, or service planning services for their children with ASD (Mereoiu, Bland, Dobbins, \& Niemeyer, 2015). Current studies highlight the importance of positive parenting and parental involvement in increasing child and parent outcomes (Burrell \& Borrego, 2012); and the influences of siblings on development of children with ASD (O'Brien, Slaughter \& Peterson, 2011). Therefore training parents on positive parenting may be an effective way of developing resilience in children with ASD.

Presently, there is no existing research or practical guide for improving resilience in children with ASD in African countries generally. Work found in the literature on Building resilience in children and youths, (Beyond Blue Ltd., 2017; Cesarone, 1999; Grotberg, 1995), is designed for use by parents and teachers of typically developing children population. Hence, developing culturally-based intervention programs for resilience among children with 
ASD is critical. Research has shown that behavioural intervention at an early age implies both behavioural and neurobiological outcomes, due to the neuroplasticity of young brains (Kaboski et al., 2017). To this end, efforts to improve the resilience of children with ASD could result in a physiological change in their condition.

Family-based intervention, including parent-mediated and siblings-mediated interventions, should be explored in raising resilience among children with ASD. Raising family resilience as it has been well researched is another approach that could give rise to improved resilience outcomes in their children with ASD. For instance, in a review of literature on Resilience in family members of persons with ASD, Bekhet, Johnson, and Zauszniewski (2012) found that resilient parents of children with ASD tend to manage adversities related to caring for children with ASD produce beneficial outcomes for children with ASD. Research should be intensified in improving parents' and siblings'competence in managing resources and strategies to help the children with ASD develop the resilience necessary for daily success.

Educators (including teachers, language and occupational therapists) can build trust with families and have a forum for sharing the child's weakness and strength in other to have a guided plan for intervention and support. This will help to harmonize strategies used at home and those used in the school, for consistency in professional and family strategies for improving resilience. Educators and other professionals in the stake of building resilience in children with ASD could familiarize themselves with different cultures before meeting families and see themselves as partners who care, especially in culturally diverse Africa (Bankole, 2016).

Including the child with ASD in activities at home can be stressful or chaotic (Yorke, et al., 2018), but the parents and family members should develop the resilience to work well with such children. On that note, frameworks should be developed to teach family members how to work with children with ASD in a bid to build their resilience.

There is a gap in policy on Education in the area of autism in some developing countries like Nigeria (Federal Republic of Nigeria, (FRN), 2013). The policies should spell out family supports as a means of developing resilience in children with ASD. Families can be supported financially, or through Government intervention for improving resilience in both children with ASD and their families. These could involve sponsoring training and workshops for families and teachers of children with ASD to enhance understanding of ASD and how best to teach such individuals for optimum development.

\section{Direction for Future Research and Practice}

Future researches are encouraged to develop resilience interventions targeting functional development in children with ASD in developing countries. Family-based interventions aimed at educating parents on the evidenced-based strategies for resilience development in their children with ASD would also be relevant. For instance, family intervention focusing on specific resilience factors, such as goal setting, positive relationship; managing feelings and emotions (socio-emotional learning); adapting to changes; demonstrating good communication skills; self confidence, problem-solving skills; and participation in life could help families utilize more effective approaches to resilience development in children with ASD (Anaby et al., 2014).

There is a need for research focusing on resilience development trajectories in children with ASD. This would lead to a clear understanding of the heterogeneity of symptoms and behavioural changes in children with ASD. Research shows that sometimes, children with ASD who are diagnosed at the same spectrum tend to turn out to differ significantly in outcomes over time, while in other cases; children who were diagnosed at different spectrum may turn out to attain the same outcomes (Kaboski et al., 2017). Finding out the developmental pathways, leading to these variances would be of the essence in directing families and parents' efforts towards the development of resilience in their children with ASD.

Presently, there is a gap in the literature as to how to monitor progress in the development of resilience in the children with ASD within the school and family contexts in African countries. Given the complexity of family context and resilience trajectories (Cridland, Jones, Magee, \& Caputi, 2014; McHale, Updegraff, \& Feinberg, 2016), context-specific measures are required for evaluation of family approaches. Thus researches seeking to develop a framework for individualized context-specific resilience outcomes are needed in the literature.

Research also needs to expand the area of exploring the interaction of family background and different intervention approaches to building resilience in children with ASD. Longitudinal studies would are needed to consider whether children with ASD who develops resilience retains the skill across the life span, or whether skills are lost to transitional milestones or developmental processes.

Furthermore, studies are needed in the area of moderating factors associated with resilience processes. For example, gender is a driving factor in ASD prevalence, with a prevalence ratio of 4:1 (Werling \& Geschwind, 
2013). Gender may affect how family factors impact resilience among children with ASD. There is a need for research to explore this area. Research is also needed to find out family factors that could account for the males being diagnosed more than females, together with family resilience factors that appeal more to the male children with ASD. This will help in designing effective interventions and preventive efforts that are more focused. When the family makes it a priority to support the child in learning skills and functioning independently, adaptation and resilience could be increased.

\section{Competing Interests Statement}

The authors declare that there are no competing or potential conflicts of interest.

\section{References}

Abubakar, A., Ssewanyana, D., \& Newton, C. R. (2016). A systematic review of research on autism spectrum disorders in Sub-Saharan Africa.Behavioural neurology, 2016. https://doi.org/10.1155/2016/3501910

American Psychiatric Association. (2013). Diagnostic and statistical manual of mental disorders (5th ed.). Arlington, VA: American Psychiatric Publishing. https://doi.org/10.1176/appi.books.9780890425596

Anaby, D., Law, M., Coster, W., Bedell, G., Khetani, M., Avery, L., \& Teplicky, R. (2014). The mediating role of the environment in explaining the participation of children and youth with and without disabilities across home, school, and community. Archives of Physical Medicine and Rehabilitation, 95(5), 908-917. https://doi.org/10.1016/j.apmr.2014.01.005

Anderson, K. A., Sosnowy, C., Kuo, A. A., \& Shattuck, P. T. (2018). Transition of individuals with autism to adulthood: a review of qualitative studies. Pediatrics, 141(Supplement 4), S318-S327. https://doi.org/10.1542/peds.2016-4300I

Ashburner, J., Ziviani, J., \& Rodger, S. (2010). Surviving in the mainstream: Capacity of children with autism spectrum disorders to perform academically and regulate their emotions and behavior at school.Research in Autism Spectrum Disorders, 4, 18-27. https://doi.org/10.1016/j.rasd.2009.07.002

Bakare, M. O., \& Munir, K. M. (2011). Autism spectrum disorders (ASD) in Africa: a perspective. African Journal of Psychiatry, 14(3), 208-210. https://doi.org/10.4314/ajpsy.v14i3.3

Barnhill, G. P., Polloway, E. A., \& Sumutka, B. M. (2011). A survey of personnel preparation practices in autism spectrum disorders. Focus on Autism and Other Developmental Disabilities, 26, 75-86. https://doi.org/10.1177/1088357610378292

Bekhet, A. K., Johnson, N. L., \& Zauszniewski, J. A. (2012). Resilience in family members of persons with autism spectrum disorder: A review of the literature. Issues in mental health nursing, 33(10), 650-656. https://doi.org/10.3109/01612840.2012.671441

Boonen, H., Maljaars, J., Lambrechts, G., Zink, I., Van Leeuwen, K., \& Noens, I. (2014). Behavior problems among school-aged children with autism spectrum disorder: Associations with children's communication difficulties and parenting behaviors. Research in Autism Spectrum Disorders, 8(6), 716-725. https://doi.org/10.1016/j.rasd.2014.03.008

Brede, J., Remington, A., Kenny, L., Warren, K., \& Pellicano, E. (2017). Excluded from school: Autistic students' experiences of school exclusion and subsequent re-integration into school.Autism \& Developmental Language Impairments, 2. https://doi.org/10.1177/2396941517737511

Burrell, T. L., \& Borrego Jr, J. (2012). Parents' involvement in ASD treatment: what is their role?.Cognitive and Behavioral Practice, 19(3), 423-432. https://doi.org/10.1016/j.cbpra.2011.04.003

Bush, H. H., Cohen, S. R., Eisenhower, A. S., \& Blacher, J. (2017). Parents' Educational Expectations for Young Children with Autism Spectrum Disorder. Education and Training in Autism and Developmental Disabilities, 52(4), 357-368.

Calder, L., Hill, V., \& Pellicano, E. (2013). Sometimes I want to play by myself': Understanding what friendship means to children with autism in mainstream primary schools. Autism, 17, 296-316. https://doi.org/10.1177/1362361312467866

Cappadocia, M. C., Weiss, J. A., \& Pepler, D. (2012). Bullying experiences among children and youth with autism spectrum disorders.Journal of autism and developmental disorders, 42(2), 266-277. https://doi.org/10.1007/s10803-011-1241-x

Carbone, P. S., Behl, D. D., Azor, V., \& Murphy, N. A., (2010). The medical home for children with autism 
spectrum disorders: Parent and pediatrician perspectives. Journal of Autism and Developmental Disorders, 40, 317-324.https://doi.org/10.1007/s10803-009-0874-5

Chukwueloka, V. N. (2016). Attitudes of Nigerian Mothers Toward Children With Autism Spectrum Disorder. Walden Dissertations and Doctoral Studies.

Cridland, E. K., Jones, S. C., Magee, C. A., \& Caputi, P. (2014). Family-focused autism spectrum disorder research: A review of the utility of family systems approaches. Autism: the International Journal of Research and Practice, 18(3), 213-222.https://doi.org/10.1177/1362361312472261

Crowell, J. A., Keluskar, J., \& Gorecki, A. (2019). Parenting behavior and the development of children with autism spectrum disorder.Comprehensive psychiatry, 21-29.https://doi.org/10.1016/j.comppsych.2018.11.007

Dawson, N. (2011). Ecological pespective on Parents' Experiences of Having a child with Autistic Spectrum Disorder (ASD) in the South African Context (Masters in Community Based Counselling Psychology), University of the Witwatersrand, Johannesburg.

De Caroli, M. E., \& Sagone, E. (2013). Siblings and disability: A study on social attitudes toward disabled brothers and sisters.Procedia-Social and Behavioral Sciences, $1217-1223$. https://doi.org/10.1016/j.sbspro.2013.10.018

Ennis-Cole, D., Durodoye, B. A., \& Harris, H. L. (2013). The impact of culture on autism diagnosis and treatment: Considerations for counselors and other professionals. The Family Journal, 21(3), 279-287. https://doi.org/10.1177/1066480713476834

Essien, P. U., Akpan, M. U., \& Ekanem, E. E. (2017). Autism Spectrum Disorders Among Pre-primary and Primary School Pupils in Uyo, Nigeria. American Journal of Psychiatry and Neuroscience, 5(6), 60. https://doi.org/10.11648/j.ajpn.20170506.11

Feinberg, M. E., Sakuma, K. L., Hostetler, M., \& McHale, S. M. (2013).Enhancing sibling relationships to prevent adolescent problem behaviors: Theory, design and feasibility of Siblings Are Special.Evaluation and Program Planning, 36(1), 97-106.https://doi.org/10.1016/j.evalprogplan.2012.08.003

Flippin, M., \& Watson, L. R. (2015). Fathers' and mothers' verbal responsiveness and the language skills of young children with autism spectrum disorder. American Journal of Speech-Language Pathology, 24(3), 400-410. https://doi.org/10.1044/2015_AJSLP-13-0138

Franz, L., Chambers, N., von Isenburg, M., \& de Vries, P. J. (2017). Autism spectrum disorder in sub-saharan Africa: A comprehensive scoping review. Autism Research, 10(5), 723-749.

Garbacz, S. A., McIntyre, L. L., \& Santiago, R. T. (2016). Family involvement and parent-teacher relationships for students with autism spectrum disorders. School Psychology Quarterly, 31(4), 478. https://doi.org/10.1037/spq0000157

Harker, C. M., Ibanez, L. V., Nguyen, T. P., Messinger, D. S., \& Stone, W. L. (2016). The effect of parenting style on social smiling in infants at high and low risk for ASD. Journal of autism and developmental disorders, 46(7), 2399-2407. https://doi.org/10.1007/s10803-016-2772-y

Helps, S. (2016). Systemic psychotherapy with families where someone has an autism spectrum condition.NeuroRehabilitation, 38(3), 223-230. https://doi.org/10.3233/NRE-161314

Kaboski, J., McDonnell, C. G., \& Valentino, K. (2017). Resilience and autism spectrum disorder: Applying developmental psychopathology to optimal outcome. Review Journal of Autism and Developmental Disorders, 4(3), 175-189. https://doi.org/10.1007/s40489-017-0106-4

Kavaliotis, P. (2017). Resilience of parents with a child with autism spectrum disorders and factors for its potential enhancement: Family income and educational level. Journal of Educational Developmental Psycholology, 7, 188-94. https://doi.org/10.5539/jedp.v7n1p188

Keen, D., Webster, A., \& Ridley, G. (2016). How well are children with autism spectrum disorder doing academically at school? An overview of the literature.Autism, 20, $276-94$. https://doi.org/10.1177/1362361315580962

Lai, M. C., \& Szatmari, P. (2019). Resilience in autism: Research and practiceprospects. Autism, $23(3), 539-541$. https://doi.org/10.1177/1362361319842964

Lambrechts, G., Maljaars, J., Boonen, H., van Esch, L., Van Leeuwen, K., \& Noens, I. (2015). Parenting behavior 
in mothers of preschool children with ASD: Development of a self-report questionnaire. Autism Research and Treatment, 2015. https://doi.org/10.1155/2015/381236

Martínez-Pedraza, F. D. L., \& Carter, A. S. (2009). Autism spectrum disorders in young children.Child and Adolescent Psychiatric Clinics, 18(3), 645-663. https://doi.org/10.1016/j.chc.2009.02.002

Masten, A. S., \& Tellegen, A. (2012). Resilience in developmental psychopathology: Contributions of the project competence longitudinal study. Development and Psychopathology, 24(2), 345-361. https://doi.org/10.1017/S095457941200003X

Mathew, N. E., Burton, K. L., Schierbeek, A., Črnčec, R., Walter, A., \&Eapen, V. (2019).Parenting preschoolers with autism: Socioeconomic influences on wellbeing and sense of competence. World Journal of Psychiatry, 9(2), 30. https://doi.org/10.5498/wjp.v9.i2.30

McHale, S. M., Updegraff, K. A., \& Feinberg, M. E. (2016). Siblings of youth with autism spectrum disorders: Theoretical perspectives on sibling relationships and individual adjustment. Journal of Autism and Developmental Disorders, 46(2), 589-602. https://doi.org/10.1007/s10803-015-2611-6

McHale, S. M., Updegraff, K. A., \& Whiteman, S. D. (2012). Sibling relationships and influences in childhood and adolescence. Journal of Marriage and Family, 74(5), 913-930. https://doi.org/10.1111/j.1741-3737.2012.01011.x

Mereoiu, M., Bland, C., Dobbins, N., \& Niemeyer, J. A. (2015). Exploring Perspectives on Child Care with Families of Children with Autism.Early Childhood Research \& Practice, 17(1), n1.

Minke, K. M., Sheridan, S. M., Kim, E. M., Ryoo, J. H., Koziol, N. A., (2014). Congruence in parent-teacher relationships: the role of shared perceptions. Elementary School Journal, 114, 527-546. https://doi.org/10.1086/675637

O'Brien, K., Slaughter, V., \& Peterson, C. C. (2011). Sibling influences on theory of mind development for children with ASD. Journal of Child Psychology and Psychiatry, 52(6), 713-719. https://doi.org/10.1111/j.1469-7610.2011.02389.x

Odunsi, R., Garner, P., \& Preece, D. (2017). Nigerian teachers' understanding of autism spectrum disorder: a comparative study of teachers from urban and rural Lagos State. Disability, CBR and Inclusive Development, 28(3), 98-114. https://doi.org/10.5463/dcid.v28i3.637

Ostfeld-Etzion, S., Golan, O., Hirschler-Guttenberg, Y., Zagoory-Sharon, O., \& Feldman, R. (2015). Neuroendocrine and behavioral response to social rupture and repair in preschoolers with autism spectrum disorders interacting with mother and father. Molecular autism, 6(1), 11.https://doi.org/10.1186/s13229-015-0007-2

Patterson, S. Y., Elder, L., Gulsrud, A., \& Kasari, C. (2014). The association between parental interaction style and children's joint engagement in families with toddlers with autism.Autism, 18(5), 511-518. https://doi.org/10.1177/1362361313483595

Picardi, A., Gigantesco, A., Tarolla, E., Stoppioni, V., Cerbo, R., Cremonte, M., ... \& Nardocci, F. (2018). Parental burden and its correlates in families of children with autism spectrum disorder: A multicentre study with two comparison groups. Clinical practice and epidemiology in mental health: CP \& EMH, 14, 143. https://doi.org/10.2174/1745017901814010143

Simelane, A. (2015). The role of resilience and socio-economic status in the parenting of children with autism spectrum disorder in South Africa (Doctoral dissertation).Aining in Developmental Disabilities, 44(4), 444.

Ting, V., \& Weiss, J. A. (2017).Emotion regulation and parent co-regulation in children with autism spectrum disorder.Journal of autism and developmental disorders, 47(3), 680-689. https://doi.org/10.1007/s10803-016-3009-9

Ungar, M. (2013). Resilience, trauma, context and culture.Trauma, Violence, \& Abuse, 14, 253-264. https://doi.org/10.1177/1524838013487805

Ungar, M. (2015). Practitioner review: Diagnosing childhood resilience - A systemic approach to the diagnosis of adaptation in adverse social and physical ecologies. Journal of Child Psychology and Psychiatry, 56, 4-17. https://doi.org/10.1111/jcpp.12306

Van Biljon, S., Kritzinger, A., \& Geertsema, S. (2015). A retrospective case report on demographic changes of learners at a school for children with Autism Spectrum Disorders in the Gauteng Province. South African 
Journal of Childhood Education, 5(1), 01-26.

Walsh, F. (2016). Family resilience: A developmental systems framework. European Journal of Developmental Psychology, 13(3), 313-324. https://doi.org/10.1080/17405629.2016.1154035

Werling, D. M., \&Geschwind, D. H. (2013).Sex differences in autism spectrum disorders.Current opinion in neurology, 26(2), 146. https://doi.org/10.1097/WCO.0b013e32835ee548

Woo, A. H. (2009). Siblings of Children with Disabilities: Examining Sibling Well-being and Sibling Relationship Quality. ProQuest.

Wright, B. M., \& Benigno, J. P. (2019). Autism Spectrum Disorder and Sibling Relationships: Exploring Implications for Intervention Using a Family Systems Framework. American Journal of Speech-Language Pathology, 28(2), 759-767. https://doi.org/10.1044/2018_AJSLP-18-0088

Yorke, I., White, P., Weston, A. Rafia, M., Charman, T., \& Simonoff, E. (2018). The Association Between Emotional and Behavioral Problems in Children with Autism Spectrum Disorder and Psychological Distress in Their Parents: A Systematic Review and Meta-analysis. Journal of Autism and Developmental Disorders. 48(10), 3393-3415. https://doi.org/10.1007/s10803-018-3605-y

\section{Copyrights}

Copyright for this article is retained by the author(s), with first publication rights granted to the journal.

This is an open-access article distributed under the terms and conditions of the Creative Commons Attribution license (http://creativecommons.org/licenses/by/4.0/). 